\title{
Special issue dedicated to the 8th international conference on optimization and applications (OPTIMA 2017)
}

\author{
Alexander P. Afanasiev ${ }^{1} \cdot$ Michael Khachay $^{1} \cdot$ Yury Kochetov $^{1}$ \\ Published online: 3 October 2019 \\ ๑) Springer-Verlag GmbH Germany, part of Springer Nature 2019
}

\section{Preface}

This special issue contains 18 out of 33 papers submitted by the participants of the 8th International conference "Optimization and Applications" OPTIMA 2017, which was held in Petrovac, Montenegro, at the picturesque place of the Budvanian riviera, on October 2-7, 2017. Like previous OPTIMA conferences, this conference was intended to bring together researchers and practitioners working in the field of optimization theory, methods, software and related fields.

The conference was organized by the Montenegrin Academy of Sciences and Arts, University of Montenegro, the Federal Research Center "Computer Science and Control" of Russian Academy of Science (Russia), University of Evora (Portugal), and Institute of Information and Computational Technologies (Kazakhstan).

The papers included to this issue can be partitioned to the following topical sections:

- theory and methods of continuous optimization,

- optimal control and game theory,

- graph theory and data niming,

- mathematical economics,

- applications.

As guest editors, we would like to cordially thank all authors for their submissions and all the reviewers for their fruitful comments, which helps us to make this issue better. Also, we would like to express our appreciation to the Montenegrin Academy of Sciences and Arts, University of Montenegro, Prof. Milojica Jacimovic, Acad. Yury Evtushenko, Prof. Mikhail Posypkin, and all the Montenegrin colleagues for organization of the conference in this beautiful place. Our special gratitude to the Editors-in-Chief of Optimization Letters, Prof. O. Prokopyev and Prof.

Alexander P. Afanasiev

apa@iitp.ru

1 Institut Matematiki Imeni S L Soboleva SO RAN, Novosibirsk, Russian Federation 
P. Krokhmal for their kind support. We hope that the reader will find papers of this special issue helpful and enjoyable.

\section{Guest Editors:}

Alexander P. Afanasiev, Michael Khachay, and Yury Kochetov.

Publisher's Note Springer Nature remains neutral with regard to jurisdictional claims in published maps and institutional affiliations. 